\title{
Absence of a response-rate-dependent effect of d-amphetamine on a DRL schedule when reinforcement is signaled
}

\author{
ROBERT J. CAREY and R. PETER KRITKAUSKY* \\ VA Hospital and State University of New York Upstate Medical Center \\ Syracuse, N.Y. 12310
}

In two experiments, the effect of a $1-\mathrm{mg} / \mathrm{kg}$ dose of d-amphetamine on operant responding for water on a DRL 22 -sec schedule was investigated. If the water reinforcement was signaled by a change in illumination, this dose of amphetamine did not affect response or reinforcement rate. In the absence of an external stimulus correlated with reinforcement, however, amphetamine markedly increased response rate and decreased reinforcement rate on this schedule. Timing behavior was disrupted regardless of whether reinforcement was signaled or nonsignaled.

It is well documented that amphetamine markedly increases the low operant-response rates maintained by differential reinforcement of low-rate (DRL) schedules of reinforcement (Kelleher \& Coats, 1959; Schuster \& Zimmerman, 1961). This effect of amphetamine fits nicely within the response rate dependent frame work suggested by Dews (1958), namely, that amphetamine increases low-rate performance but decreases high-rate performance. In addition to response rate, however anothe;important behavioral determinant of the effect of amphetamine is the type of stimulus control under which the behavior is maintained. Laties \& Weiss (1966) and Heise \& Lilie (1970) have shown that a dose of amphetamine which markedly impairs performance on a task under the control of internal stimuli interferes little or not at all with performance on the same task when it is under the control of external stimuli. Since responding on a DRL schedule is controlled by internal stimuli, this consideration suggests that the facilitative effect of amphetamine on a DRL schedule might be sharply attenuated if the DRL performance were developed under the control of an external stimulus. The present experiments evaluate this possibility.

\section{EXPERIMENT 1 \\ Subjects}

Four naive male Sprague-Dawley rats housed individually were used as Ss.

\section{Apparatus}

Operant responding for water reinforcement was studied in four operant chambers housed individually in sound-insulated enclosures. Each

*Current address: Department of Psychology. University of Louisville, Louisville, Ky. 40208. chamber contained a single 1-1/8 $\mathrm{x}$ $3 / 8$ in. lever which projected $1 \frac{1 / 4}{\text { in. }}$ into the chamber. The lever was mounted $2 \frac{1 / 4}{\mathrm{in}}$. above the chamber floor and required a 15 -g force (1/8-in. displacement) to activate an attached microswitch. Water reinforcement was delivered by a solenoid assembly which allowed unlimited access to a 0.05-cc dipper cup. Each chamber compartment was illuminated during the test period by a $24-\mathrm{V}$ dc miniature lamp bulb mounted at the top center of the side panel. White noise was broadcast continuously into each chamber to help mask external sounds. Switching circuits with timers and digital counters automatically programmed reinforcement, recorded responses, and controlled session durations.

DRL performance was evaluated by recording the number of responses emitted per session and the number of reinforcements obtained per session. The temporal pattern of responding was also measured by recording the interresponse times (IRTs) in 112 -sec class intervals.

\section{Procedure}

Throughout testing, all animals were maintained on a water-deprivation regimen of $30 \mathrm{~min}$ of water per day. Initially, all animals were trained to leverpress on a continuous reinforcement schedule (CRF).

Nonsignaled $D R L$ training. Once the response was well established, all animals were given 151 -h sessions under a DRL 22-sec schedule of water reinforcement with an unlimited hold. By Session 15, all rats developed interresponse time distributions indicative of "timing" behavior, which is characteristic of DRL responding.

Signaled DRL training. On Sessions 16-18, the animals were tested with the same schedule in effect but, in addition, were provided a light cue which signaled reinforcement availability. This was accomplished by having the houselight go off when reinforcement was available.

Amphetamine tests. Next, the rats were divided into two groups of two each. For one group, the testing sequence was: Session 19-unsignaled DRL, no drug; Session 20-unsignaled DRL, $1 \mathrm{mg} / \mathrm{kg}$ d-amphetamine sulfate; Session 21-signaled DRL, no drug; Session 22 -signaled DRL, $1 \mathrm{mg} / \mathrm{kg}$ d-amphetamine. On Sessions 23-26, this testing sequence was repeated. For the second group, the same no-drug/drug sequence was followed, except that testing was started with the signaled rather than the unsignaled DRL schedule.

\section{Results}

Overall mean performance in terms of response and reinforcements on the signaled and the unsignaled DRL with and without amphetamine is presented in Table 1. As expected, under the nonsignaled DRL condition, amphetamine markedly increased responding and decreased the number of reinforcements obtained. Separate $t$ tests for related measures showed that both the increased number of responses and decreased number of reinforcements under amphetamine were statistically significant $(p<.01)$. When reinforcement was signaled on the DRL schedule, however, amphetamine had but a slight nonsignificant effect $(p>.25)$ on the response and reinforcement rates. The mean IRT distributions for the nonsignaled DRL and for the signaled

Table 1

Means and Standard Deviations of Responses and Reinforcements Obtained in Experiment 1 on Signaled vs Nonsignaled DRL With and Without Amphetamine

\begin{tabular}{|c|c|c|}
\hline Testing Sequence & Responses & Reinforcements \\
\hline & \multicolumn{2}{|c|}{ Signaled } \\
\hline No Drug 1 & $73.0 \pm 4.9$ & $49.5 \pm 4.3$ \\
\hline Amphetamine 1 & $76.7 \pm 10.8$ & $45.5 \pm 5.2$ \\
\hline No Drug 2 & $82.2 \pm 11.4$ & $51.0 \pm 10.0$ \\
\hline \multirow[t]{2}{*}{ Amphetamine 2} & $90.7 \pm 10.9$ & $49.5 \pm 10.3$ \\
\hline & \multicolumn{2}{|c|}{ Nonsignaled } \\
\hline No Drug 1 & $109.7 \pm 17.3$ & $32.0 \pm 9.2$ \\
\hline Amphetamine 1 & $193.7 \pm 36.1$ & $11.7 \pm 3.7$ \\
\hline No Drug 2 & $117.2 \pm 22.4$ & $30.2 \pm 11.9$ \\
\hline Amphetamine 2 & $204.7 \pm 47.8$ & $7.5 \pm 2.5$ \\
\hline
\end{tabular}




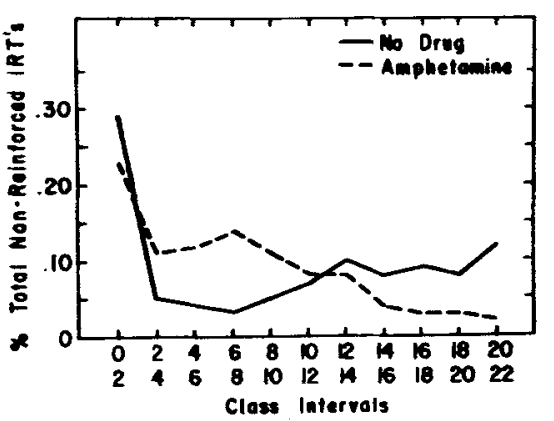

Fig. 1. Mean relative frequency of nonreinforced interresponse times in each of 112 -sec class intervals generated in the DRL nonsignaled test sequences.

DRL with and without amphetamine are presented in Figs. 1 and 2, respectively. As can be seen in Figs. 1 and 2 , the effect of amphetamine on this aspect of DRL performance was similar for both the signaled and the nonsignaled conditions. Thus, amphetamine did affect performance on the signaled DRL, but only in terms of the temporal distribution of responses.

\section{EXPERIMENT 2 \\ Subjects}

Six naive male Sprague-Dawley rats, approximately $400 \mathrm{~g}$ in weight, were used.

\section{Procedure}

Initially, the effects of a $1-\mathrm{mg} / \mathrm{kg}$ subcutaneous injection of d-amphetamine on activity level in a photobeam cage was determined for each animal. On the basis of these results, the animals were divided into two groups of three each equated in terms of activity. All animals were then maintained on $30 \mathrm{~min}$ of water per day throughout experimentation. After all animals were trained to barpress, one-half of the group was placed on a nonsignaled DRL 22-sec schedule and the other half on a signaled DRL 22-sec schedule. For the signaled condition, the houselight

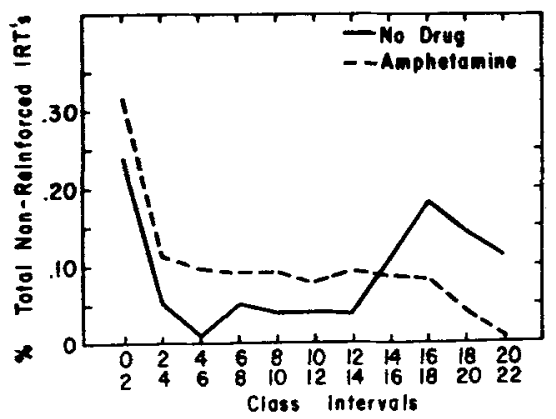

Fig. 2. Mean relative frequency of nonreinforced interresponse times in each of 112 -sec class intervals generated in the DRL signaled test sequence.

Table 2

Means and Standard Deviations of Responses and Reinforcements Obtained in Experiment 2 on a DRL Schedule Under Signaled vs Nonsignaled Condition With and Without Amphetamine

\begin{tabular}{|c|c|c|c|c|}
\hline & \multicolumn{2}{|c|}{ No Drug } & \multicolumn{2}{|c|}{ Amphetamine } \\
\hline & Responses & Reinforcements & Responses & Reinforcements \\
\hline \multicolumn{5}{|l|}{ Group 1} \\
\hline Signaled & $127.3 \pm 7.1$ & $74.0 \pm 2.6$ & $146.6 \pm 28.6$ & $64.6 \pm 19.1$ \\
\hline Nonsignaled & $163.3 \pm 17.7$ & $43.0 \pm 12.1$ & $249.3 \pm 49.6$ & $13.0 \pm 3.6$ \\
\hline \multicolumn{5}{|l|}{ Group 2} \\
\hline Nonsignaled & $162.6 \pm 13.2$ & $38.3 \pm 9.2$ & $226.6 \pm 20.5$ & $17.6 \pm$ \\
\hline Signaled & $134.3 \pm 8.0$ & $68.0 \pm 10.4$ & $132.6 \pm 20.6$ & $68.6 \pm 9.3$ \\
\hline
\end{tabular}

went on whenever a reinforcement was available and remained on until the reinforcement was obtained. Otherwise, the houselight was always off. For the nonsignaled condition, the houselight was always off. This stimulus arrangement is just the opposite of that in Experiment 1. Each animal was run on daily $45-\mathrm{min}$ sessions until it reached a criterion of $40 \%$ reinforced responses on the signaled DRL or $20 \%$ reinforced responses on the nonsignaled DRL. After a criterion session was reached, an animal was given a $1-\mathrm{mg} / \mathrm{kg}$ subcutaneous injection of d-amphetamine $30 \mathrm{~min}$ prior to testing on the next DRL session. Following this amphetamine session, the animal's DRL condition (signaled vs nonsignaled) was reversed. Daily test sessions were then run until the animals reached criterion for this particular DRL condition. Again, once a criterion performance was achieved, the animal was given the same $1 \cdot \mathrm{mg} / \mathrm{kg}$ subcutaneous injection of d-amphetamine $30 \mathrm{~min}$ before its next and final DRL session.

\section{Results}

Table 2 compares DRL performance in terms of responses and reinforcements on the criterion session with the amphetamine session for the signaled and nonsignaled DRL condition. Again, as expected, amphetamine increased response rate but decreased reinforcemen rate on the nonsignaled DRL. Separate $t$ tests for related measures performed on the combined performances of Groups 1 and 2 resulted in significant $t$ values $(p<.01)$ for both the increased responses and decreased reinforcements under amphetamine. Amphetamine did not affect performance on the signaled DRL, as indicated by these two measures of performance $(p>.25)$. As in Experiment 1, however, the IRT distribution shifted to short IRTs under amphetamine.

\section{DISCUSSION}

The results of both experiments show that the facilitative effect of a $1-\mathrm{mg} / \mathrm{kg}$ dose of d-amphetamine on
DRL responding does not occur when reinforcement is signaled by an external stimulus. This finding provides good support for the observations of Heise \& Lilie (1970), that amphetamine has a much more disruptive effect on internally than on externally controlled behavior. Furthermore, the results of this study minimize the significance of response rate when it is compared with the type of stimulus control as a determinant of the effect of amphetamine. This conclusion stems from the fact that amphetamine had little or no effect on response rate under the signaled condition, whereas it markedly increased a higher response rate maintained by the nonsignaled DRL condition. It is also interesting to note that the temporal pattern of responding on the signaled DRL was disrupted by amphetamine. This result seems significant in that this impairment of "timing behavior" occurred in the absence of a change in response or reinforcement rates. This result suggests that the breakdown in temporal patterning on a DRL schedule under amphetamine is not simply secondary to a state of hyperresponding.

\section{REFERENCES}

DEWS, $P$ B Analysis of effects of pharmacological agents in behavioral terms. Federation Proceedings, 1958, 17 , $1024-1030$.

HEISE, G. A., \& LILIE, N. L. Effects of scopolamine, atropine, and d-amphetamine on internal and external control of responding on nonreinforced trials. Psychopharmacologia, 1970, 18, 38-50.

KELLEHER, R. J., \& COATS, L. Effects of d-amphetamine, meprobamate. phenobarbital, mephenesin, or chlorpromazine on DRL and FR schedules of reinforcement with rats. Journal of the Experimental Analysis of Behavior, 1961, 4, 327-330 (Abstract).

LATIES, V. G., \& WEISS, B. Influence of drugs on behavior controlled by intemal and external stimuli. Journal of Pharmacology \& Experimental Therapeutics, $1966,152,388-396$.

SCHUSTER, C. R., \& ZIMMERMAN, J Timing behavior during prolonged treatment with d-amphetamine. Journal of the Experimental Analysis of Behavior, $1961,4,327-330$. 